\title{
Dosage-sensitive modifiers of Drosophila abl tyrosine kinase function: prospero, a regulator of axonal outgrowth, and disabled, a novel tyrosine kinase substrate
}

\author{
Frank B. Gertler, Kevin K. Hill, Michael J. Clark, and F. Michael Hoffmann \\ McArdle Laboratory for Cancer Research, University of Wisconsin, Madison, Wisconsin 53706 USA
}

In the absence of the Drosophila abl protein-tyrosine kinase (PTK), loss-of-function mutations in either disabled or prospero have dominant phenotypic effects on embryonic development. Molecular and genetic characterizations indicate that the products of these genes interact with the abl PTK by different mechanisms. The interaction between $a b l$ and prospero, which encodes a nuclear protein required for correct axonal outgrowth, is likely to be indirect. In contrast, the product of disabled may be a substrate for the abl PTK. The disabled protein is colocalized with abl in axons, its predicted amino acid sequence contains 10 motifs similar to the major autophosphorylation site of abl, and the protein is recognized by antibodies to phosphotyrosine.

[Key Words: Drosophila; Abelson; tyrosine kinase; genetic modifiers; neural development]

Received August 27, 1992; revised version accepted December 21, 1992.

Drosophila that are $a b l^{-}$die as fully formed adults either in the pupal case (pharate adults) or shortly after eclosion with normal external structures other than roughened eyes (Henkemeyer et al. 1987). Given the mild phenotypes of $a b l$ mutant animals, it was possible to design genetic screens to identify mutations in genes that enhance or suppress the $a b l$ mutant phenotypes (Gertler et al. 1989, 1990; Hoffmann 1991). We hypothesized that in a genetic background sensitized by $a b l$ mutations, a $50 \%$ reduction in the level of a protein that is regulated by abl might be sufficiently detrimental to shift the lethal phase from the pharate adult stage to an embryonic or early larval stage. We have found that heterozygosity for a mutation in any one of three independent loci identified in screens of $\sim 16,000$ mutagenized chromosomes exacerbates the $a b l$ mutant phenotype to embryonic or larval lethality (Gertler et al. 1989; M. Visalli, E. Liebl, M.J. Clark, and F.M. Hoffmann, unpubl.). We have called this effect haploinsufficiency dependent on an $a b l$ mutant background (HDA). The genes identified to date are not haploinsufficient themselves but manifest their effects when the fly is also mutant for $a b l$. disabled $(d a b)$ and prospero (pros) are two of the genes identified by this strategy.

We have reported previously on the phenotypic effects of $d a b$ mutations (Gertler et al. 1989). Although $a b l \mathrm{mu}$ tant embryos exhibit no visible defects in the embryonic central nervous system (CNS), animals that are doubly mutant for $a b l$ and $d a b$ die as embryos and fail to form proper axonal connections in the CNS. The presence of a single copy of either gene largely restores the axonal architecture, indicating functional redundancy between the two gene products. A function for the abl proteintyrosine kinase (PTK) in embryonic axonogenesis is also revealed in animals mutant for both $a b l$ and fas $I$; fas $I$ encodes a neural cell adhesion molecule expressed at the time of axon fasciculation (Elkins et al. 1990). The phenotypic defects observed in $a b l d a b$ and $a b l$ fas $I$ embryos are consistent with the increased levels of abl protein detected in the axons of the embryonic CNS /Gertler et al. 1989; Elkins et al. 1990; Bennett and Hoffmann 1992).

In this report we provide further evidence for the role of $a b l$ in axonogenesis by identifying a second HDA as the pros gene. pros has been identified independently by four other laboratories using enhancer-trap methods (Doe et al. 1991; Vassein et al. 1991; Matsuzaki et al. 1992; C. Klambt and C. Goodman, pers. comm.). The pros gene product is a nuclear protein required for proper differentiation and axonal outgrowth of embryonic neurons and is detected in ganglion mother cells and some glial cells (Vaessin et al. 1991). We also report on the molecular identification of $d a b$. The $d a b$ expression pattern is similar to that of abl, including increased levels of the dab protein in CNS axons and body wall muscles. Analysis of its nucleotide sequence predicts that the dab 
protein contains sites for tyrosine phosphorylation similar to the major autophosphorylation site in abl and three 11-amino-acid stretches of alternating acidic and basic residues, but no other significant similarities to known proteins. A mechanism for its genetic interactions with abl is suggested by the observation that the dab protein is recognized by antibodies to phosphotyrosine and therefore is a putative substrate for the Drosophila abl tyrosine kinase.

\section{Results}

\section{Genetics of the HDA mutant M4}

Genetic screens for second-site enhancer mutations of the $a b l$ mutant phenotype recovered the M4 and M44 HDAs. Meiotic recombination mapping placed the M4 mutation on the right arm of chromosome 3, between curled and stripe (Gertler et al. 1989). Overlapping multigenic deletions were used to map the recessive lethality associated with M4 and M44 to polytene region $86 \mathrm{E}$ 2-10, and two P-element enhancer-trap lines [1(3)86E and $\operatorname{pros}^{139}$, each of which contained an insertion in this region, were found to be allelic to the M4 and M44 mutations. Because the locus defined and isolated using these P-element insertions had been named pros (Doe et al. 1991), we renamed the M4 HDA pros ${ }^{M 4}$ and the M44 HDA pros ${ }^{\text {M44. }}$.

Table 1 illustrates the shift in lethal phase of $a b 1 \mathrm{mu}$ tant animals (HDA effect) observed with pros mutations using deletions $\left[D f(3 R) T-61\right.$ or pros $\left.{ }^{17}\right]$, null alleles $\left(\operatorname{pros}^{M 4}\right.$, or $\left.\operatorname{pros}^{M 44}\right)$, or a hypomorphic allele $\left(\right.$ pros $\left.^{139}\right)$. pros $^{139}$ generated a weak HDA effect; such a mutation would not have been detected in our screen for HDA mutations had we used $P$ elements as a mutagen. The P-element revertant allele, pros ${ }^{17}$, which contains a small deficiency, does not produce a detectable transcript and behaves as a genetic null (Doe et al. 1991). pros $^{17}$ had phenotypic and genetic behavior indistinguishable from that of the pros ${ }^{M 4}$ allele. $D f(3 R) T-61$ also produced an HDA effect, demonstrating formally that the loss of one gene copy of pros exacerbates the $a b 1$ mutant phenotype. A transposon carrying an $a b l$ gene $\left(\mathrm{P}\left[a d h^{+}, a b l^{+}\right]\right.$; Henkemeyer et al. 1987) permitted full recovery of viable adults, thereby demonstrating that pros haploinsufficiency occurred only in the absence of $a b l$.

\section{Phenotypes in embryos mutant for pros, abl, and dab}

To investigate the nature of the genetic interaction between $a b l$ and pros, we assayed the phenotype of the embryonic CNS using antibodies that recognize the axons of the CNS (Fig. 1A). As shown in Table 1, heterozygous deletions of pros in the absence of $a b l$ caused embryonic and larval lethality. Examination of these embryos revealed, for the most part, normal axonal architecture in the CNS and peripheral nervous system (PNS) with variably penetrant subtle defects in the CNS,
Table 1. Quantitation of the pros HDA effect

\begin{tabular}{llrc}
\hline $\begin{array}{l}a b 1 \\
\text { genotype }\end{array}$ & $\begin{array}{l}\text { pros } \\
\text { genotype }\end{array}$ & $\begin{array}{l}\text { Flies } \\
(\%)^{\mathrm{a}}\end{array}$ & $\begin{array}{l}\text { Flies }+ \\
\text { pupae }(\%)^{\mathrm{b}}\end{array}$ \\
\hline$a b 1^{-}$ & pros $^{+} /$pros $^{+}$ & 49 & 70 \\
$a b 1^{-}$ & pros $^{139} /$ pros $^{+}$ & 28 & 45 \\
$a b 1^{-}$ & pros $^{17} /$ pros $^{+}$ & 6 & 6 \\
$a b 1^{-}$ & pros $^{\text {M4 }} /$ pros $^{+}$ & 5 & 16 \\
$a b 1^{-}$ & pros $^{\text {M4 }} /$ pros $^{+}$ & 2 & 11 \\
$a b 1^{-}$ & Df(3R)T-61/pros & 4 & $-{ }^{\mathrm{c}}$ \\
$\mathrm{P}\left[a d h^{+}, a b 1^{+}\right]$ & pros $^{\text {M4 }} /$ pros $^{+}$ & $166^{\mathrm{d}}$ & 152 \\
\hline
\end{tabular}

The generation of the mutant progeny is described in Materials and methods. Mutant pupae and adult flies could be distinguished by the lack of the dominant marker $T b$, carried by the balancer chromosome. All $a b 1^{-}$adults displayed the $a b l$ mutant phenotype (Henkemeyer et al. 1987).

${ }^{a}$ Represented are the total number of $T b^{+}$rough-eyed $a b l \mathrm{mu}$ tant flies scored as a percentage of the expected progeny class size. The expected progeny class size was estimated by dividing the total number of $T b$ flies from each cross by two.

bIncluded are both the $T b^{+}$adult flies and the $T b^{+}$pharate adults that had not eclosed after the eighteenth day of each brood. The total progeny scored from each cross ranged from 3000 to 6000 flies and pupae.

'The third chromosomes were balanced by the TM6,B balancer chromosome, except for the $a b l^{1}, D f(3 R) T-61$ chromosome, which did not survive well over TM6, $B$ and was balanced by the TM3 balancer chromosome. For this reason, we were unable to score the genotype of the pupae in this cross.

${ }^{\mathrm{d}}$ Flies that carried one copy of $\mathrm{P}\left[a d h^{+}, a b 1^{+}\right]$were phenotypically normal. Values $>100 \%$ from the $\mathrm{P}\left[a d h^{+}, a b l^{+}\right]$cross may reflect the partial, dominant lethality of the two TM6, $B$ balanced progeny classes in addition to the true rescue of the $a b l$ mutant lethality.

including fusion of the anterior and posterior commissural axon bundles.

pros $^{M 4}$ mutant embryos displayed a segmentally repeated pattern of disrupted axon bundles in each neuromere (Fig. 1E) indistinguishable from the pros CNS phenotypes reported previously (Doe et al. 1991). The longitudinal axons, which extend anteriorly and posteriorly between segments, were absent. The midline space between the two halves of the nervous system was wider than normal, with a loss of some midline cells of unknown identity. The anterior and posterior commissural axon bundles that cross the midline in each segment were replaced by a single axon bundle. These phenotypes were also observed in pros protein-null embryos mutant for the overlapping deficiencies $D f(3 R) K x 1$ and $D f(3 R) T E 32$ (data not shown). In contrast, embryos that were homozygous mutant for the hypomorphic allele pros $^{139}$ had an axonal phenotype indistinguishable from wild type, although $76 \%$ of the embryos of this genotype failed to hatch (data not shown). However, an intermediate phenotype was observed when the pros ${ }^{139}$ allele was heterozygous with a deletion of pros or a null allele of pros: The anterior and posterior commissures failed to separate completely and remained somewhat fused or closely apposed, often resulting in a single, thickened commissure (Fig. 1C). 


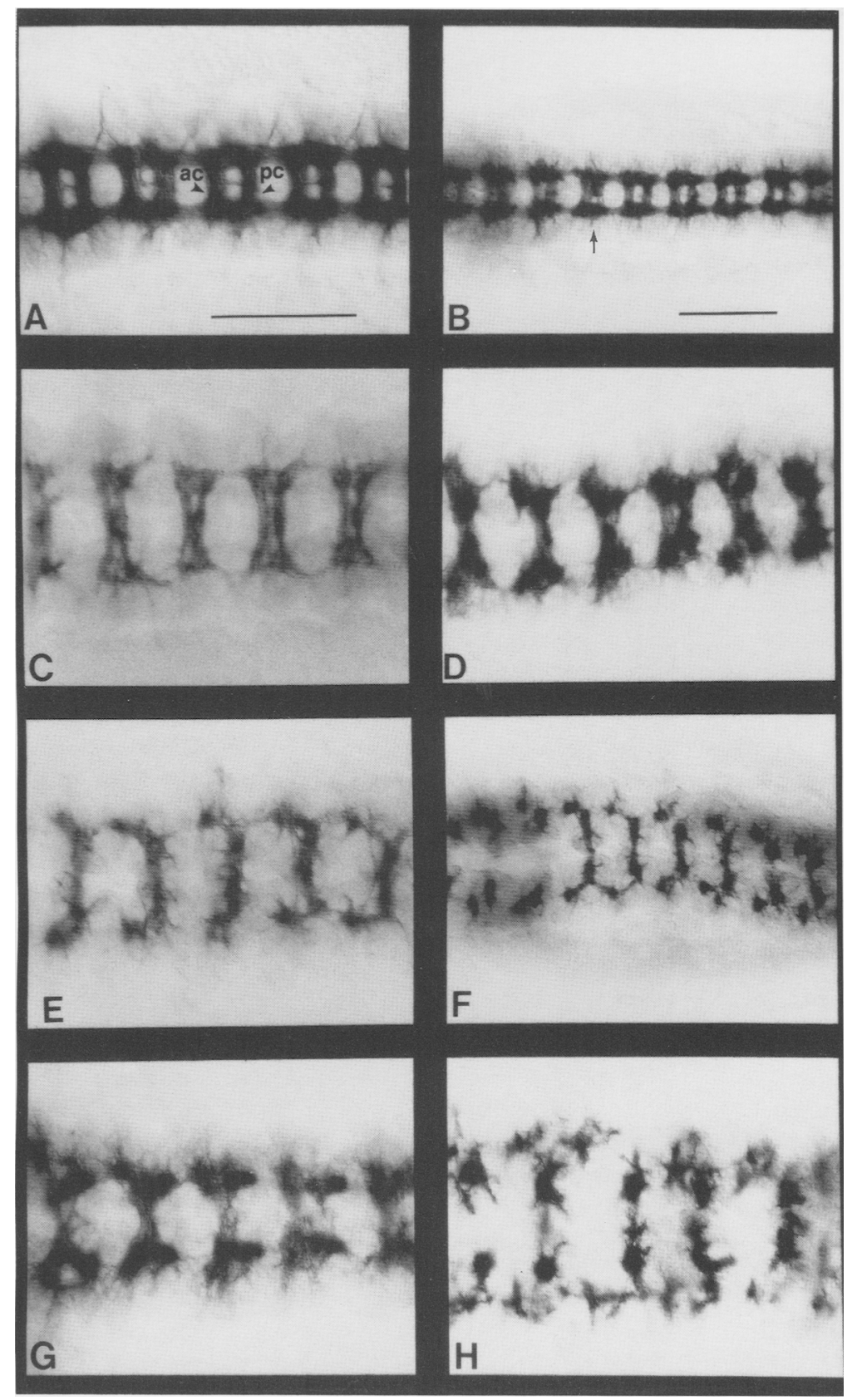

Figure 1. CNS phenotype of mutant embryos. Embryonic nerve cords were stained with the CNS-specific antibody BP102 to visualize the axon bundles of the CNS. In all panels, anterior is to the left. (A) A wild-type embryonic CNS, early stage 15. The anterior $(\mathrm{ac})$ and posterior $(\mathrm{pc})$ commissural axon bundles that cross the ventral midline in each segment are indicated. Bar, $50 \mu \mathrm{m} .(B)$ The CNS from an $a b 1^{-}$pros $^{\mathrm{M} 4} / \mathrm{abl}^{-}$pros $^{+}$mutant, middle stage 15 . The structure of the CNS was similar to wild type, but small defects were occasionally observed such as the defective commissural bundle indicated by the arrow. Bar, $50 \mu \mathrm{m}$. (C) The CNS from a pros $^{139} /$ pros $^{-}$embryo, stage 13 or 14 . pros $^{139}$ was induced by insertion of a $\mathbf{P}$ element and displayed hypomorphic activity. The anterior and posterior commissural axon bundles in each segment were closer together than in wild type $(A)$ but not completely fused as in the pros null embryo $(E)$. (D) The CNS from an $a b 1^{-}$ pros $^{139} / \mathrm{abl}^{-}$pros $^{-}$embryo, middle stage 15 . The commissural axons were closely apposed as in $C$, indicating that the absence of $a b l$ function did not detectably alter the $\operatorname{pros}^{139}$ phenotype. $(E)$ The CNS from a $\operatorname{pros}^{M 4}$ homozygote, early stage 15 . The null phenotype of pros, as initially reported by Doe and colleagues (1990), included the complete fusion of the anterior and posterior commissural axon bundles and absence of the longitudinal axon bundles between the segments. $(F)$ The CNS from an $a \mathrm{bl}^{-}$pros $^{-}$mutant embryo, early stage 15 . The absence of $a b l$ function did not detectably alter the pros null phenotype. The break in the thoracic commissural bundles was an artifact of slide preparation. $(G)$ The CNS from an $a b I^{-} d a b^{-}$mutant embryo, middle stage 15 . As originally reported by Gertler and colleagues (1990), the double mutation caused the absence of most intersegmental longitudinal axon bundles and most commissural axon bundles. $(H)$ The CNS from an $a b 1^{-} d a b^{-}$pros $^{-}$ triple mutant embryo, late stage 15 . The longitudinal and commissural axon bundles were completely disrupted consistent with an additive effect of the pros mutant phenotype $(E)$ and the $a b l d a b$ double mutant phenotype $(G)$.

Embryos that were double mutant for both $a b l$ and pros displayed CNS phenotypes indistinguishable from those of pros mutant embryos (Fig. 1C-F). Even the intermediate phenotype caused by the pros hypomorphic allele was not detectably altered by the absence of $a b l$ (Fig. 1C,D). As $a b l^{-}$embryos rarely exhibited a detectable mutant phenotype in the embryonic CNS, a phenotype similar to the pros $^{-}$phenotype alone was consistent with an additive genetic interaction between $a b l$ and pros.

Because mutations of $d a b$ and pros were identified in the same genetic screen, we expected that the double HDA mutant phenotype might be more severe than ei- ther single mutant phenotype. For example, animals bearing transheterozygous mutations in neurogenic genes (Artavanis-Tsakonas 1988) or genes involved in ventral cell fate determination (Simpson 1983) exhibit synergistic phenotypic effects. However, hemizygosity for pros had no effect on the CNS immunostaining of animals hemizygous for $d a b$ in an $a b l$ mutant background or homozygous mutant for both $a b l$ and $d a b$ (data not shown|. In addition, the dab pros double mutant embryo had a phenotype indistinguishable from the pros mutant phenotype (data not shown).

Embryos that were triple mutant for $a b l, d a b$, and pros displayed few axons. Clusters of neuronal cells could be 
detected with short axonal or dendritic processes, but the overall axonal architecture of the CNS was mostly absent (Fig. 1H). This phenotype led us to ask whether the neuronal cells were present but not able to extend axons or whether the neurons were extending axons but no longer presenting the antigen recognized by BP102, and thereby escaping detection. To address these questions, triple mutant embryos were stained with anti-engrailed antibody to detect neuronal cells and anti-HRP antibodies as an alternative probe for detecting axons (Jan and Jan 1982). The anti-engrailed staining indicated that the neuronal cells were present, even up to stage 16 embryos, albeit expressing engrailed in the altered pattern seen in pros mutants alone (Fig. 2; Doe et al. 1991). The anti-HRP staining revealed a phenotype similar to that obtained with BP102, that is, few axons were detected (data not shown). The earliest disruption of axonogenesis was observed at stage 13 , as was the case in $a b l$ dab double mutants (Henkemeyer et al. 1990). We conclude that these phenotypes reflect an additive effect of the absence of pros (Fig. 1E) and the absence of $a b l$ and $d a b$ (Fig. 1G) on the ability of terminally differentiated neurons to extend axons.

\section{Molecular cloning of $d a b$}

$d a b$ was mapped to the 73B5-7 region through its dosagesensitive interaction with mutations in $a b l$ (Henkemeyer et al. 1987; Gertler et al. 1989). The HDA effect was used to map the $d a b$ gene by testing chromosomal deletions to determine whether hemizygosity for the region caused the characteristic exacerbation of the $a b l$ mutant phenotype. These studies placed $d a b$ in the interval between the proximal endpoints of the chromosomal deletions $D f(3 L) s t E 34\left(d_{a b}{ }^{+}\right)$and $D f(3 L)$ st $100.62\left(d^{2} b^{-}\right)$, corresponding to the region $73 \mathrm{~B} 5-7$ on the cytological map (Henkemeyer et al. 1987). DNA from the proximal side of the $a b l$ gene (Belote et al. 1990) was used to initiate a walk in which $100 \mathrm{~kb}$ of DNAs proximal to the initial probe and spanning the interval between the two deletion breakpoints were recovered from a cosmid library (Fig. 3).

To identify coding regions, restriction enzyme-digested fragments from cosmid clones spanning the $50 \mathrm{~kb}$ of DNA between the two deletion breakpoints were used as probes to screen cDNA libraries. Three classes of cDNAs were recovered and named $B, M$, and $C$. The longest cDNAs of each class $(4.5,5$, and $5.6 \mathrm{~kb})$ failed to cross-hybridize, suggesting that they corresponded to independent messages (data not shown). The organization of these cDNAs in the genome was then mapped by Southern hybridization to cloned DNA from the chromosome walk and genomic DNA (Fig. 3). The M cDNA hybridized to a repetitive sequence in the genome.

To determine whether the C cDNA corresponded to the $d a b$ transcriptional unit, $35 \mathrm{~kb}$ of genomic DNA in a cosmid P-element transformation vector (Fig. 3) was introduced into the germ line to test for its ability to compensate for $d a b$ mutations. To assay for $d a b$ function, the P-element cosmid was introduced into an $a b 1^{-}$

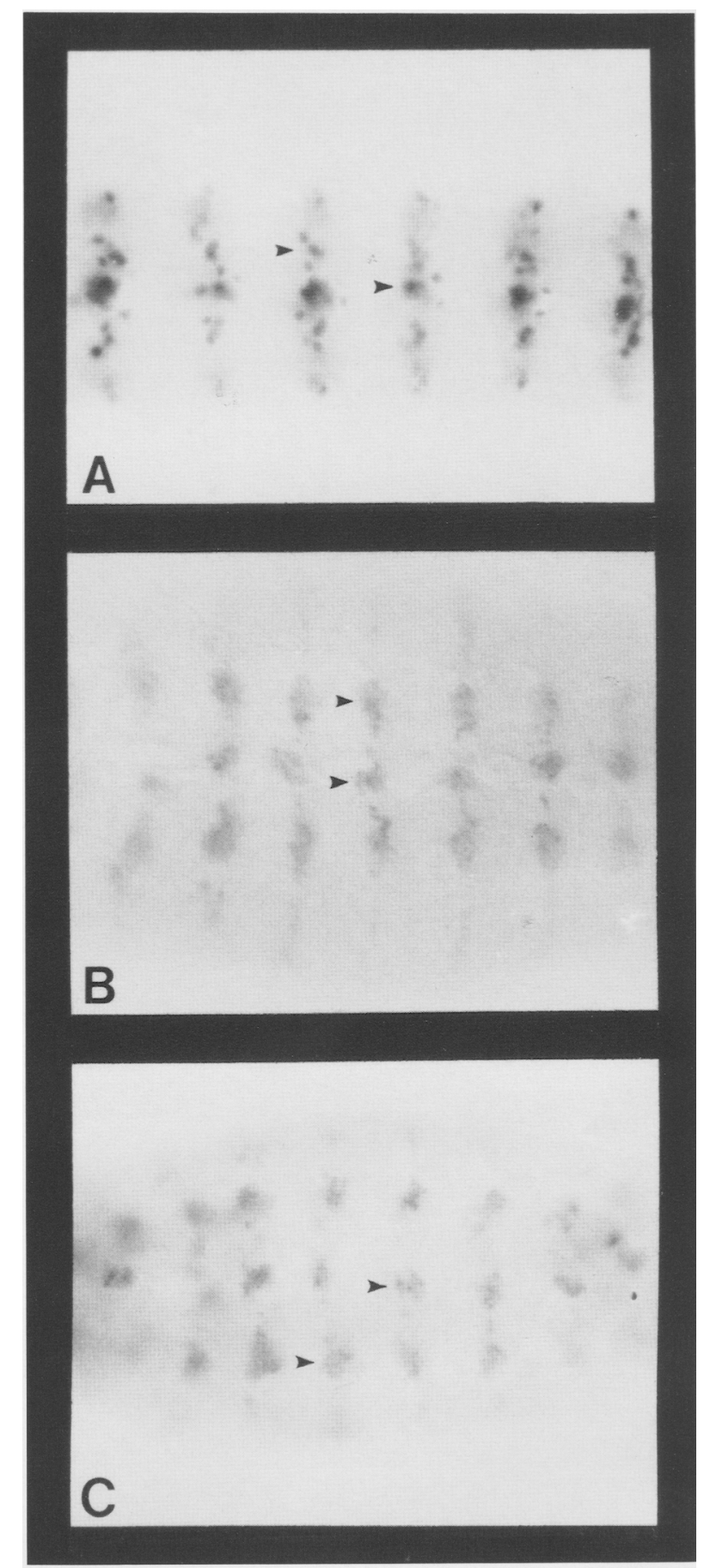

Figure 2. Pattern of neurons expressing engrailed in wild-type and mutant embryos. In all panels, anterior is to the left. Arrowheads point to clusters of midline and lateral neuronal cells that express engrailed. At different optical planes, one can observe single cells expressing engrailed. $(A)$ A wild-type embryonic CNS, early stage 15. (B) A pros null mutant embryo, stage 14. There was an increase in the number of lateral and midline cells expressing engrailed at each optical plane. (C) An $a b I^{-}$ $d a b^{-}$pros $^{-}$embryo, stage 14 . The increased number of lateral and midline cells expressing engrailed was indistinguishable from that observed in pros mutant embryos $(B)$ although the neurons in the triple mutant embryos generated fewer axon bundles than in the pros mutant embryos (Fig. 1E,H). 


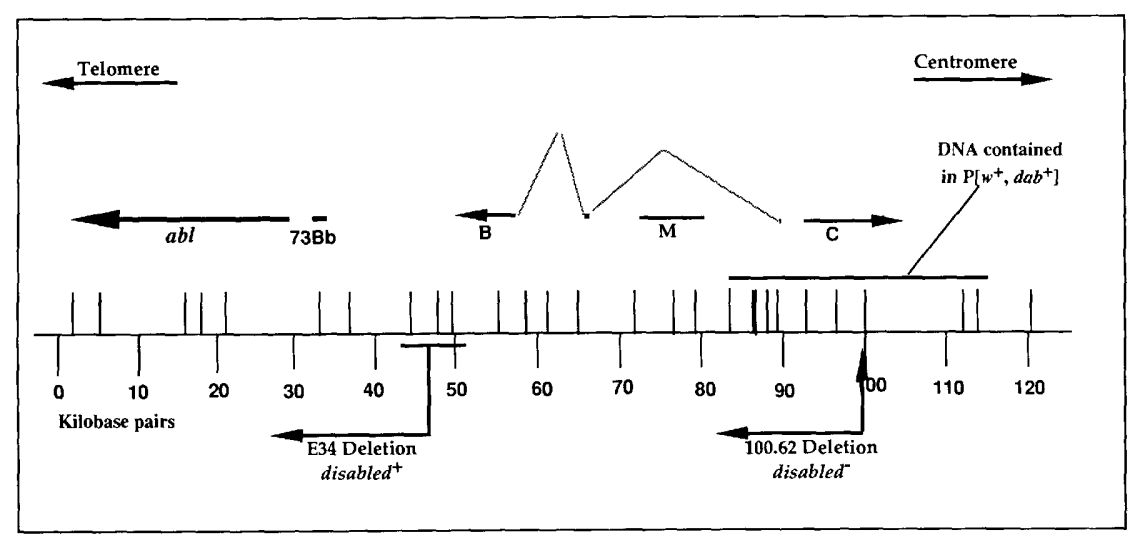

Figure 3. Molecular map of DNA from chromosome region 73B,C. The $a b l$ and $1(3 L) 73 B b$ loci are indicated (Henkemeyer et al. 1987). Three classes of cDNAs, C, M, and $B$, are depicted above the restriction map based on their pattern of hybridization to genomic and cloned DNA. The arrows point in the direction of transcription based on the directional cloning of the cDNAs. Restriction endonuclease EcoRI sites are indicated by the vertical lines above the horizontal line. The numbers below the line indicate the distance, in $\mathrm{kbp}$, from the $3^{\prime}$ end of the $a b l$ gene. The map is oriented such that left to right corresponds to distal (telomere) to proximal (centromere) on chromosome arm 3L. The portion of the DNA removed by the $D f(3 L) s t E 34$ and $D f(3 L) s t 100.62$ deletions extends to the left /distal) of the breakpoints indicated on the map. The deletion breakpoints were localized by Southern blotting and in situ hybridization to polytene chromosomes (Gertler 1992). The segment of DNA contained in the P-element cosmid vector $\mathrm{P}\left[w^{+}, d a b^{+}\right]$is indicated (positions 83-115). $\mathrm{P}\left[\mathrm{w}^{+}, d a b^{+}\right]$contained the entire region hybridizing to the C cDNA and at least $5 \mathrm{~kb}$ of flanking DNA on both the $5^{\prime}$ and $3^{\prime}$ ends of the message. It was unlikely that the DNA in the cosmid encoded any other functional embryonic genes in addition to the gene represented by the C cDNA. No other embryonic transcripts, except those represented by the B and C cDNAs, were identified by the DNA contained in the cosmid when portions of this DNA were hybridized to Northern blots or used to screen cDNA libraries (data not shown). Only $\sim 500 \mathrm{bp}$ of the $5^{\prime}$ end of the B cDNA was represented in the cosmid, and the most $5^{\prime}$ nucleotide of this cDNA was $2.5 \mathrm{~kb}$ from the cap site of the transcript represented by the C cDNA (see below). Finally, if there were transcripts from this region that we failed to detect, the genes encoding these transcripts must be deleted or disrupted by the $D f(3 L)$ st 100.62 breakpoint for these genes to be candidates for the HDA gene as discussed above. As shown, most of the cosmid DNA included in the $D f(3 L)$ st 100.62 deletion is occupied by the transcription units identified by the C and B cDNAs.

$d a b^{-} / a b 1^{-} d a b^{+}$mutant background by a genetic cross. The mutant progeny of this cross were scored for frequency of survival to pupation, which is characteristic of the simple $a b 1$ mutant phenotype (Table 2). Only a modest level of rescue was observed with a single copy of the transgene; however, a graded increase in the percentage of rescued animals resulted when one to three additional independent inserts of the cosmid were introduced into the same background. Four copies of the transgene were sufficient to restore almost fully the viability of the mutant progeny class to pupal/adult lethality. The transgene functioned in an allele-independent manner as rescue was observed in backgrounds either hemizygous for . $d a b$ by deletion or heterozygous for the $d a b^{m 2}$ allele $(\mathrm{Ta}-$ ble 2). The requirement for multiple copies of the $d a b$ transgene to provide the equivalent of a single gene dose in the rescue assay may have resulted from insufficient levels of $d a b$ expression owing to insertional position effect. It is also possible that a cis-acting regulatory region or an unidentified, alternately used exon was absent from the cosmid, thus diminishing its function.

A second test for dab function by the transgene exploited the observation that mutations in $d a b$ uncover a requirement for abl tyrosine kinase activity. As reported previously, flies expressing catalytically inactive abl protein were fully viable with wild-type eyes. However, the catalytically inactive abl protein was not sufficient to rescue the $a b 1^{-} d a b^{-} / a b 1^{-} d a b^{+}$background (Henkemeyer et al. 1990). Two doses of the $d a b$ transgene and the transgene expressing catalytically inactive abl in the $a b l^{-} d a b^{-} / a b 1^{-} d a b^{+}$genetic background resulted in recovery of phenotypically wild-type adults at a fre- quency similar to that obtained in animals that carried a normal gene dosage of $d a b$ (Table 2). Taken together, these observations indicated that the transgene provided

Table 2. Rescue of dab mutations by transposon

\begin{tabular}{|c|c|c|c|}
\hline $\begin{array}{l}a b l \\
\text { genotype }\end{array}$ & $\begin{array}{l}d a b \\
\text { genotype }\end{array}$ & $\begin{array}{l}\text { Copies of } \\
\mathrm{P}\left[\mathrm{w}^{+}, d a b^{+}\right]^{\mathrm{a}}\end{array}$ & $\begin{array}{l}\text { Survival } \\
\text { to pupation } \\
(\%)\end{array}$ \\
\hline$a b 1^{-}$ & + & 一 & 100 \\
\hline$a b 1^{-}$ & $d a b^{-} / d a b^{+}$ & 0 & 5 \\
\hline$a b 1^{-}$ & $d a b^{-} / d a b^{+}$ & 1 & 20 \\
\hline$a b 1^{-}$ & $d a b^{-} / d a b^{+}$ & 2 & 27 \\
\hline$a b 1^{-}$ & $d a b^{-/ d a b^{+}}$ & 3 & 40 \\
\hline$a b 1^{-}$ & $d a b^{-} / d a b^{+}$ & 4 & 85 \\
\hline $\mathrm{P}\left[a d h^{+}\right.$, & $d a b^{-} / d a b^{+}$ & 0 & 98 \\
\hline$\left.a b 1^{+}\right]$ & & & $(91 \% \text { to adults })^{b}$ \\
\hline $\begin{array}{l}\mathrm{P}\left[a d h^{+},\right. \\
\left.a b l^{\text {lys-}}\right]\end{array}$ & $d a b^{-} / d a b^{+}$ & 0 & $(16 \% \text { to adults })^{\mathrm{c}}$ \\
\hline $\begin{array}{l}\mathrm{P}\left[a d h^{+},\right. \\
\left.a b l^{\text {ys }}{ }^{-}\right]\end{array}$ & $d a b^{-} / d a b^{+}$ & 2 & $\begin{array}{c}93 \\
(80 \% \text { to adults })^{b}\end{array}$ \\
\hline
\end{tabular}

Mutant genotypes were generated as described in Materials and methods. The $d a b$ genotype represents the state of the endogenous $d a b$ gene and does not include the $d a b$ transgene.

andicated are the number of P-element $d a b$ transgenes present. The percentage given represents the fraction of the expected mutant progeny class that survives to pupation or adulthood as calculated from the number of non-mutant siblings in the same cross. $\mathrm{P}\left[a d \mathrm{~h}^{+}, a b \mathrm{l}^{\mathrm{lys}^{-}}\right]$encodes a kinase-defective version of $\mathrm{abl}$ (Henkemeyer et al. 1990).

${ }^{b}$ These animals were phenotypically wild type.

'These animals were rough-eyed and short lived, phenotypes which are typical of $a b 1^{-}$adults (Henkemeyer et al. 1987). 
$d a b$ activity and that the C cDNA corresponded to the $d a b$ message.

\section{Sequence of dab}

The $d a b$ message is $\sim 8-8.5 \mathrm{~kb}$ as determined by Northern blot hybridization to embryonic mRNA or adult head mRNA (Gertler 1992). Because the 5.6-kb dab cDNA was too short to be full length, two approaches, screening a randomly primed library made from Drosophila adult head mRNA and the anchored polymerase chain reaction (PCR), the "RACE" method (Frohman et al. 1988), were used to isolate more $5^{\prime}$ cDNA. The nucleotide sequence of the entire cDNA, RACE product, and $750 \mathrm{bp}$ of upstream genomic DNA was determined (data not shown). At the $5^{\prime}$ end, the sequence of the RACE product was entirely colinear with the genomic DNA except for a guanidine base at the extreme $5^{\prime}$ end of the longest clone, which was not present in the genomic sequence; no variance between the genomic sequence and those of five shorter RACE products was observed. Either the $5^{\prime} \mathrm{G}$ in the RACE product represented an authentic cap or it was introduced by a fidelity error in the PCR. No conventional TATA or CAAT motifs were found in the vicinity of the putative start site.

The longest open reading frame (ORF) in the sequence spanned $7254 \mathrm{bp}$ with the alternately included exon. There were stop codons in all three reading frames within $100 \mathrm{bp}$ upstream of this reading frame, thereby delimiting the extent of potential coding sequence. The only methionine codon in the first 480 bp of this ORF matched the consensus for translational starts in Drosophila (Cavener 1987) and may be the in vivo initiation site. Conceptual translation of the ORF (Fig. 4) predicted proteins of either 2411 or 2198 amino acids, depending on the inclusion of the alternatively spliced exon. The GENPEPT and SWISSPROT data bases were searched using the FASTA program (Devereaux et al. 1984), but no sequences with extensive similarity to $d a b$ were detected. No potential transmembrane hydrophobic domains were found in the sequence. The predicted dab protein contained an 11-amino-acid motif, which was repeated three times in a 110 -amino-acid interval. This motif consisted of alternating glutamic or aspartic acid and arginine residues. The dab sequence also contained 10 matches to a motif for tyrosine phosphorylation found in abl. Eight of the potentially phosphorylated tyrosines in dab fell in a 170-residue region that included all three acid-base repeats; computer analysis of the protein structure predicted that this region is likely to be exposed on the surface of the protein.

\section{Distribution of dab during embryogenesis}

The embryonic expression pattern of $d a b$ mRNA, examined by in situ hybridization to whole-mount embryos (Gertler 1992), included uniform expression from blastoderm through gastrulation. At the end of germ-band extension, higher levels of $d a b$ mRNA were detected in the mesoderm and in the CNS. Polyclonal rabbit antibody to dab was used to detect the protein in whole-mount embryos and gave results consistent with $d a b$ mRNA localization studies. dab protein null embryos were used to provide an indication of nonspecific background staining (Fig. 5H-L). In the cellular blastoderm, immunohistochemical staining for dab protein was observed in the
Figure 4. Deduced amino acid sequence of dab. A translation of the $d a b$ ORF, including the alternately used exon, is shown. Amino acids 462-673 are removed by the alternate splice. Potential sites for tyrosine phosphorylation $[(\mathrm{K}, \mathrm{R}) 2-3 \mathrm{X}(\mathrm{D}, \mathrm{E}) 2-3 \mathrm{X} \mathrm{Y}]$ are indicated by bold lettering (amino acids: 111, 482, $1662,1667,1701,1704,1713,1739,1826,1961$ ). A tyrosine residue in this context would occur at a frequency of $1 / 887$ amino acids in random ORFs. The 1521-amino-acid Drosophila abl protein contains one match to this tyrosine phosphorylation consensus, residue 543 , which corresponds to the in vivo autophosphorylation site for v-abl (Konopka et al. 1984). Of the 10 potential tyrosine phosphorylation sites in dab, 8 are clustered within a 170-amino-acid interval that also contains the three 11 -amino-acid stretches of alternating acidic and arginine residues (underlined: 1689-1700, 1740-1750, 1791-1801). Data bases were searched using the FASTA program, but no significant similarity to dab was found. Matches to the site for tyrosine phosphorylation [(K,R) 2-3X (D,E) 2-3X Y] (Hunter and Cooper 1986) were identified with the Motifs algorithm. The sequence data described here have been submitted to the EMBL/GenBank data libraries under accession number L08845.

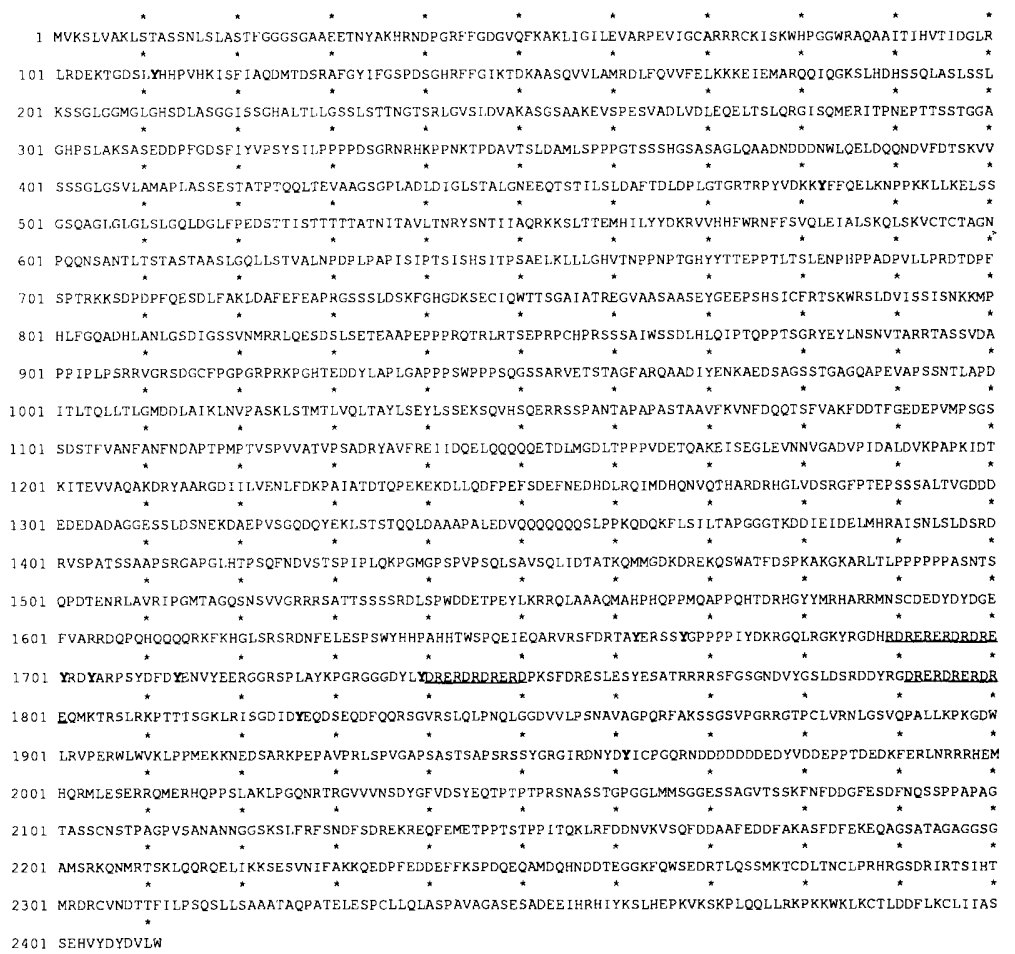




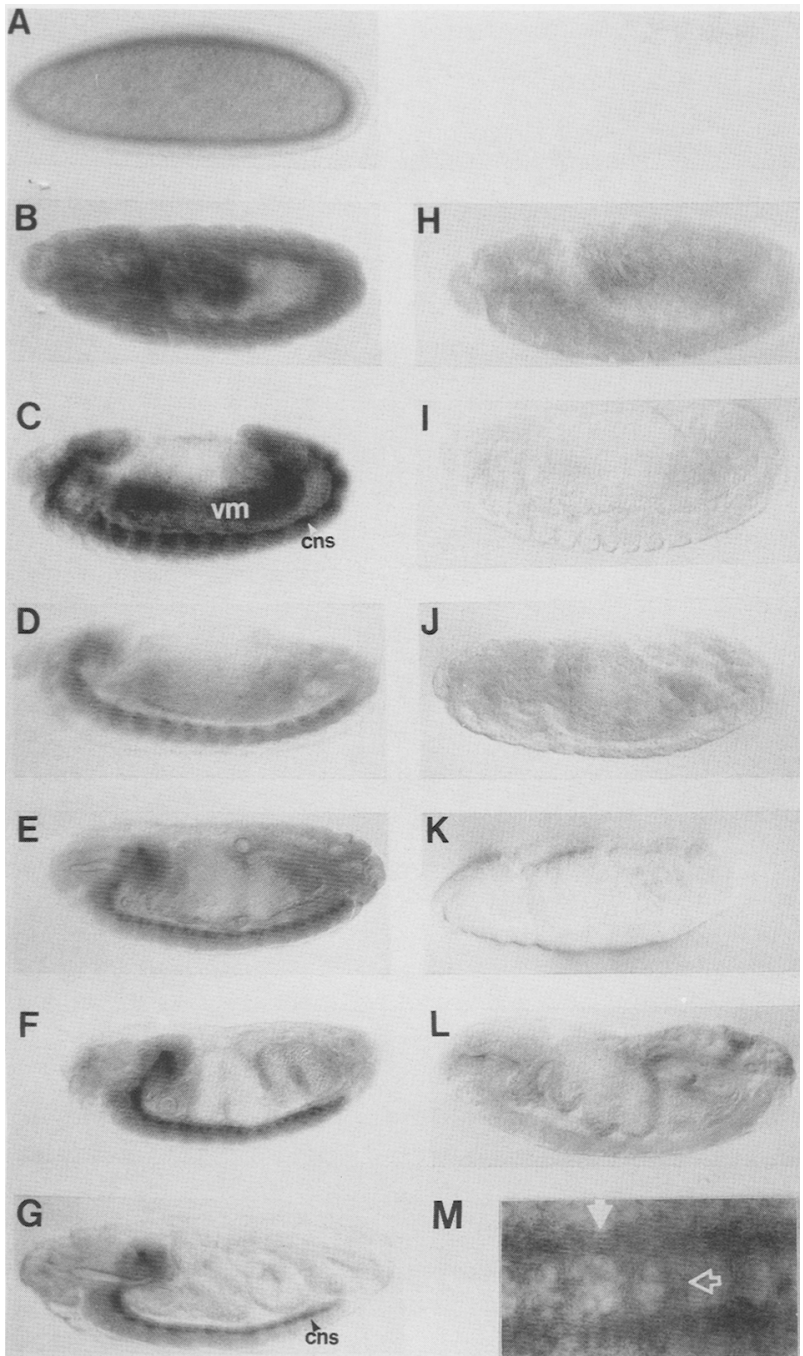

Figure 5. Distribution of dab protein during embryogenesis. dab protein expression was relatively uniform through the embryo at early stages $(A, B)$, but at later stages, levels of dab expression were higher in the CNS, especially in the axon bundles $(E, F, G, M)$. Embryos were fixed and stained with anti-dab antibodies as described in Materials and methods. $A-G$ and $M$ are wild-type animals; $H-L$ are dab protein-null mutants that were present in the experiment as internal negative controls for antibody specificity. All embryos are oriented anterior left and dorsal up, except for $A$, which is ventral side up, and $M$, which is a higher magnification view of the ventral nerve cord. (vm) Visceral mesoderm. Arrowheads in $C$ and $G$ indicate the CNS. In $M$, the closed white arrowhead indicates the longitudinal axon bundle; the open arrowhead denotes a commissural axon bundle. $(A)$ Cellular blastoderm; $(B, H)$ germ-band-extended embryos; $(C, I)$ stage 12 embryos; $(D, I)$ stage 13 embryos; $(E, K)$ stage 14 embryos; $(F, L)$ stage 15 embryos; $(G)$ stage 16 embryo; $(M)$ ventral view of stage 15 embryo nerve cord.

cytoplasm and not the nuclei (Fig. 5A). During gastrulation, dab protein was broadly distributed (Fig. 5B) but during germ-band retraction, higher levels of dab immunostaining were observed in the mesoderm and CNS
(Fig. 5C). Later in development, the signal in the CNS was concentrated in the axon bundles (Fig. 5D-G,M). dab protein was also detected in PNS cell clusters and the body wall musculature (Gertler 1992).

\section{$d a b$ and $a b l$ proteins contain phosphotyrosine}

Polyclonal anti-dab and anti-abl were used for Western blot and immunoprecipitation (IP) assays. To verify that anti-dab was specific, Western analyses were performed on wild-type embryos and embryos that lacked zygotic dab protein owing to deletions that remove the $d a b$ locus (Fig. 6). The slowest migrating protein recognized by anti-dab was consistent with the predicted size of the dab protein and was not detected in extracts from the mutant embryos. The faster migrating species that were immunoreactive with anti-dab may represent processed forms or degradation products of the intact protein.

To determine whether dab is a substrate for PTK activity in vivo, Drosophila Schneider 2 (S2) cells were lysed in IP buffer, and antibodies to dab, abl, or phosphotyrosine were used to precipitate the proteins. Immunoglobulins purified from the preimmune serum of the rabbit immunized with dab were also used. Aliquots of the IPs were subjected to Western blot analysis with anti-abl $(A)$, anti-dab (B), anti-phosphotyrosine (C) or, as a control, preimmune immunoglobulins $(\mathrm{D})$ to verify the presence of dab or abl proteins in the immunoprecipitates. Immunoreactive signals corresponding to abl (Fig. 7A)

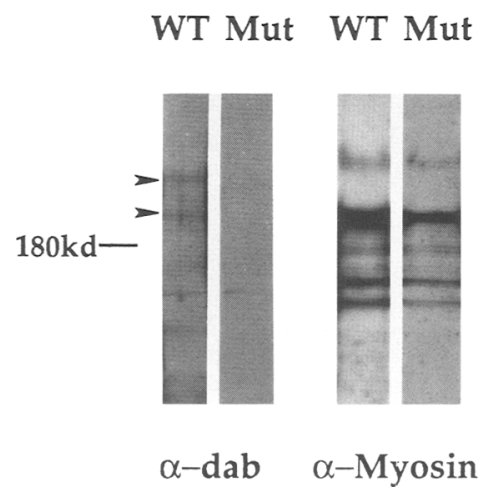

Figure 6. Western blot analysis on wild-type and $d a b$ null embryos. Pools of 10 wild-type embryos (WT) and 10 embryos transheterozygous for two multigenic deletions that each remove the $d a b$ locus (MUT) were each lysed and Western blotted. The blot was probed with anti-dab $(\alpha$-dab); an 8-min exposure is shown. After a 2-hr exposure, no additional bands were observed in the MUT lane (not shown). Two major bands (arrowheads) migrating at $\sim 250$ and $220 \mathrm{kD}$ were detected in the WT but not the MUT lane. The presence of a single band of nonspecific cross-reactivity at $\sim 150 \mathrm{kD}$ co-migrating in both the WT and MUT lanes is consistent with equal protein loading. The blot was stripped and reprobed with anti-muscle-myosin $(\alpha-m y o s i n$; gift of Daniel Kiehart, Duke University, Durham, NC). Myosin immunoreactivity was detected in both the WT and MUT lanes, confirming that protein from the mutant embryos was present on the filter. 


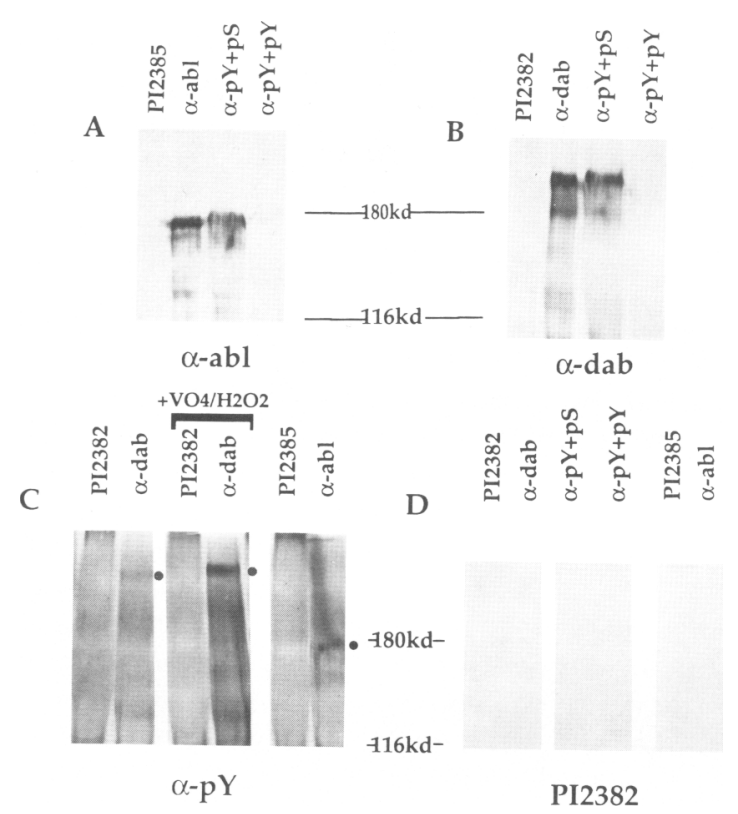

Figure 7. Western blot analysis of anti-abl, anti-dab, and antiphosphotyrosine immunoprecipitates. Lysates were made from S2 cells and immunoprecipitated with antibodies to abl, dab, or phosphotyrosine. The immunoprecipitates were Western blotted with antibodies to abl $(A)$, dab $(B)$, phosphotyrosine $(C)$, or preimmune immunoglobulin $(D)$. Anti-abl immunoreactive material was detected in anti-abl and anti-phosphotyrosine immunoprecipitates $(A)$, with the major band migrating slightly below the $180-\mathrm{kD}$ marker. Anti-dab immunoreactive material was detected in anti-dab and anti-phosphotyrosine immunoprecipitates $(B)$. The major cross-reactive band migrated slower than a $220-\mathrm{kD}$ marker. Preimmune immunoglobulins (PI2385 and PI2382) did not immunoprecipitate proteins detected by anti-abl or anti-dab on Western blots $(A, B$, first lanes $)$. Preincubation of the anti-phosphotyrosine antibodies with free phosphotyrosine blocked their ability to immunoprecipitate abl or dab $(A, B$, last lanes). Preimmune immunoglobulin PI2382, when used in Western blotting, did not recognize any proteins in the immunoprecipitates $(D)$. The anti-dab and anti-abl immunoprecipitates were Western blotted with antibody to phosphotyrosine $(C)$. The cross-reactive bands, marked by a dot, migrated in positions indistinguishable from the major bands of $\mathrm{dab}$ and $\mathrm{abl}\left\{C_{t}\right.$ lanes 2 and 6$\}$ and were not recognized in immunoprecipitates with preimmune immunoglobulins $(D$, lanes 1,3,5). Preincubation of cells with a phosphotyrosine phosphatase inhibitor (+ VO4/H2O2) enhanced the signal, marked by a dot, to a protein immunoprecipitated with anti-dab $(D$, lane 4, Heffetz et al. 1990).

and dab (Fig. 7B) were detected in immunoprecipitates with anti-abl, anti-dab, and anti-phosphotyrosine. Immunoprecipitation of abl or dab by anti-phosphotyrosine was blocked by the addition of free phosphotyrosine (Fig. $7 \mathrm{~A}, \mathrm{~B}$, right-most lanes). To corroborate this observation, anti-phosphotyrosine antibodies were used to detect proteins in immunoprecipitates from S2 cells. Bands corresponding in size to dab and abl were detected by the anti-phosphotyrosine antibodies in the immunoprecipitates of anti-dab and anti-abl, respectively $(C)$.

\section{Discussion}

We have suggested that abl, dab, and other HDA products may participate in the formation of a multimeric structure, or a dynamic process, which is sensitive to the stoichiometry of the individual components and which is especially critical for normal axonogenesis (Hoffmann 1991). We hypothesize that the function of the abl PTK is to compensate for defects in this process caused by normal variation in the levels of gene expression, some of which could be the result of loss of heterozygosity caused by somatic mutation in one of the genes encoding a component of the complex or of defects caused by the normal stochastic variation that occurs in any developmental process. The observation that development proceeds relatively normally in the absence of abl kinase activity (Henkemeyer et al. 1990) indicates that other PTKs are involved in the homeostasis or feedback regulation, or that phosphorylation by the abl PTK fine-tunes a process that works reasonably well without the regulation provided by tyrosine phosphorylation.

\section{Differences in the genetic properties of $\mathrm{dab}$ and pros}

Although the heterozygous loss-of-function mutations of pros and $d a b$ have similar genetic interactions with $a b l$ mutations, homozygous mutations of pros and $d a b$ differ in their genetic interactions with $a b 1$ mutations. The phenotype caused by homozygous mutations in $d a b$ becomes much more severe in animals also mutant for $a b l$, that is, there is a synergistic phenotypic interaction between mutations in $a b l$ and dab (Gertler et al. 1989; Bennett and Hoffmann 1992). pros ${ }^{-}$phenotypes are not detectably altered in animals also mutant for $a b l$ or $d a b$. This result is consistent with a simple additive interaction between mutations in pros and mutations in $a b l$ or with the conclusion that the severity of the pros mutant phenotype masks any defects caused by the absence of $a b l$ or $d a b$.

In another genetic test, pros and dab mutations were assayed for interactions with mutations in enabled (ena). The ena mutations act as dominant genetic suppressors to rescue the lethality caused by homozygous mutations in either $a b l$ or dab (Gertler et al. 1990). Mutations in ena also largely restore the normal embryonic CNS axonal architecture to $a b l d a b$ double mutant embryos and can substitute for the abl kinase activity in this process (Gertler et al. 1990). In contrast, no effect of the ena mutations was detected on either the lethality or axonal phenotypes caused by mutations in pros /data not shown).

\section{Differences in protein localization and timing of expression}

Further support for the hypothesis that the $a b l$ and $d a b$ products interact more directly than the $a b l$ and pros products comes from analyses of the protein expression patterns. abl protein produced from zygotic gene activation is not detectable until after the initial formation of 
the CNS and is initially detected in neurons, but not in the neuronal precursors, the neuroblasts, and the ganglion mother cells (Bennett and Hoffmann 1992). In contrast, detectable levels of pros protein have been reported specifically in the ganglion mother cells but not in mature neurons (Vaessin et al. 1991). pros protein was also detected in the glial cells used by axons for pathfinding (Vaessin et al. 1991). Although it is possible that abl and pros protein expression overlaps below detectable limits in the neurons, the available data indicate that the proteins are present at prominent levels at different times in the development of neural cells. Furthermore, the proteins are detected in different subcellular locations: pros protein is detected in the nucleus (Vaessin et al. 1991), whereas Drosophila abl protein has not been detected in the nucleus of neural cells or other cell types. Instead, the highest levels of abl protein are localized to the axonal compartment of the neuronal cells. Two explanations as to why mutations in pros were recovered as dominant genetic enhancers of the $a b l$ mutant phenotype are a $50 \%$ reduction in the level of pros function in the ganglion mother cells leads to reduced levels of multiple gene products that participate with abl in axonogenesis, or pros activity is required for optimal function of the glial cells used by pioneering axons for an $a b l-$ dependent pathfinding process. Both of these explanations predict that the biochemical mechanism for the genetic interaction between $a b l$ and pros is quite indirect.

In contrast to the differences between abl and pros expression, dab, like abl, is broadly distributed throughout early embryogenesis and gastrulation until the beginning of germ-band retraction, when the expression pattern of both proteins begins to refine. A functional requirement for $a b l$ and $d a b$ expression in early embryogenesis has not been demonstrated and will require examination of embryos from females that are germ line null for either or both $a b l$ and $d a b$. By mid-embryogenesis both abl and dab are detected in CNS axons, PNS cell clusters, the visceral mesoderm, and the somatic musculature.

\section{$d a b$ is a novel tyrosine kinase substrate}

The dab protein is immunoreactive with anti-phosphotyrosine antiserum, indicating that dab is an in vivo substrate for PTK activity in Drosophila S2 cells. These observations were made using cells that express both abl and dab endogenously, rather than a system in which the proteins were ectopically overexpressed or one in which a PTK was stimulated by oncogenic or ligand-induced activation. While there is as yet no evidence that dab is a direct substrate for the abl PTK, the similarity in the distribution of the two proteins at the cellular and subcellular levels, combined with the identification of phosphotyrosine in dab, indicate that such an interaction is possible. We have attempted to demonstrate a physical association between abl and dab by subjecting immunoprecipitates of each to Western analysis with antibody probes for the other protein. No evidence for such an association between $\mathrm{abl}$ and dab was observed in lysates of S2 cells either with or without phosphotyrosine phosphatase inhibitor treatment. However, under the conditions used, no other protein-protein interactions were detected: substrate proteins were not detected as coprecipitates with abl, and autophosphorylated PTKs were not detected as coprecipitates with dab. Therefore, the assay conditions either disrupted interactions between $\mathrm{abl}$ and its substrates and between dab and its kinase or were not sensitive enough to detect associated proteins. Unfortunately, the antibodies available for the immunoprecipitations were directed against domains of the two proteins that might be required for physical association: the $\mathrm{SH} 3, \mathrm{SH} 2$, and kinase domains of abl, and the acidbase repeat domain of dab. It will be useful to generate antibodies to other regions of the two molecules as such antibodies may permit the copurification of molecules that are associated with abl and dab in vivo.

The acid-base repeat domain of dab is predicted to the on the surface of the protein by computer analysis, indicating that it may be involved in protein-protein interactions. Longer stretches of acid-base repeats are found in some proteins involved in RNA splicing, including the U1 70-kD snRNP (Theissen et al. 1987), suppressor of white apricot (Chou et al. 1987), and transformer (Boggs et al. 1987). All of these proteins contain longer acid-base repeats, some $>100$ amino acids, than those found in dab and are believed to be RNA-binding proteins. However the acid-base stretches are not required for RNA-binding activity (Query et al. 1989). It is unlikely that dab functions as an RNA-binding protein because dab lacks the RNP consensus octamer, which is required for RNA-binding activity in U1 70-kD snRNP and is present in many known RNA-binding proteins (Query et al. 1989; Surowy et al. 1989). Query and colleagues have proposed that the acid-base repeats in splicing proteins play a role in the protein-protein interactions involved in the formation of multimeric spliceosomes. If one or more of the eight potential tyrosine phosphorylation sites in the acid-base repeat domain of $d a b$ is the in vivo site for phosphorylation, then the net charge of the domain would be changed by phosphorylation. This suggests a mechanism by which PTK activity could regulate the affinity of the acid-base repeat domain, via its charge, for an interacting molecule. Mutagenic analysis of the in vivo tyrosine phosphorylation sites and acid-base repeat domains of dab will test the significance of these features for dab function.

The finding that dab is a tyrosine kinase substrate colocalized with abl is consistent with the hypothesis that the abl PTK compensates for the reduced level of dab function by phosphorylating dab. This hypothesis could be tested directly if an assay can be established for dab function, but the sequence of dab provides few clues to this function other than a potential site of protein-protein interaction. The abl PTK is likely to have multiple substrates because abl kinase activity can effect partial phenotypic rescue of embryonic CNS structures in $d a b$ mutant backgrounds (Gertler et al. 1989). Identification of these other substrates may provide insight into the 
specific process that abl regulates during axonogenesis, especially if one or more of the substrates has homology to a protein of known function. Such insights may also allow us to design biochemical assays for the function of the dab protein. The finding that a tyrosine kinase substrate can exhibit genetic redundancy with a tyrosine kinase also raises the questions of whether a similar mechanism could mask developmental requirements for the c-src and c-abl tyrosine kinases in the mouse and whether novel substrates discovered through genetic approaches in Drosophila have vertebrate counterparts.

\section{Materials and methods}

\section{Genetic crosses}

Flies were raised on a sucrose, cornmeal, agar, and yeast extract media at $25^{\circ} \mathrm{C}$. The mutations and chromosomes used have been described in Lindsley and Zimm (1992) or were referenced in the text.

pros HDA tests The pros ${ }^{M 4}$ allele was induced on the $D f(3 L) s t / 7$ chromosome (Gertler et al. 1989), and the pros ${ }^{M 44}$ allele was induced on the $a b 1^{1}$ chromosome (line 254C) (M. Visalli and F.M. Hoffmann, unpubl.) in screens for dominant genetic modifiers of the $a b l$ mutant phenotype. The P elementinduced allele pros ${ }^{139}$ and its revertant allele pros ${ }^{17}$ (both from C. Doe, University of Illinois at Urbana) were recombined onto the $D f(3 L)$ st $/ 7$ chromosome for comparable genetic and phenotypic analysis. The $D f(3 R) T-61$ deficiency was recombined onto an isogenized $a b l^{1}$ chromosome. To generate the mutant classes in Table 1, 50-60 virgins of $a b 1^{1} /$ TM6,B were mated to approximately equal numbers of males of the following genotypes: $D f(3 L)$ st $/ 7 /$ TM6,B or $D f(3 L)$ st $/ 7$, pros ${ }^{139} / \mathrm{TM} 6, \mathrm{~B}$ or $D f(3 L) s t / 7$,

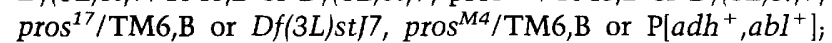
$D f(3 L) s t / 7$, pros $^{M 4} /$ TM6,B. P $\left[a d h^{+}, a b l^{+}\right]$was described by Henkemeyer et al. (1987). Virgins of $D f(3 L)$ st $/ 7 /$ TM6,B were mated to males of the following genotypes: $a b 1^{1} \mathrm{pros}^{\mathrm{M} 44} / \mathrm{TM} 6, \mathrm{~B}$ and $a b 1^{1}, D f(3 R) T-61 / \mathrm{TM} 3, \mathrm{Sb}$. All flies were brooded into new bottles every other day with seven bottles scored to completion for each cross.

dab rescue tests Crosses were set up in vials between five males and five females. The flies were transferred to fresh food daily for 7 days. At least 400 progeny were scored for each experiment. Pupae were scored for the Tubby phenotype, which results from a dominant mutation on the TM6,B balancer chromosome. Four independent second chromosome insertions of $\mathrm{P}\left[\mathrm{w}^{+}, d a b^{+}\right]$were used in the rescue experiments. To generate $a b 1^{-}$progeny, a cross was set up between white; $D f(3 L) s t / 7 /$ $T M 6 B$ males and white; $a b 1^{1} / T M 6 B$ virgin females. To generate $a b I^{-} d a b^{-} / a b I^{-} d a b^{+}$progeny, a cross was set up between white; $D f(3 L) s t / 7 d a b^{m 2} / T M 6 B$ males and white; $a b l^{1} / T M 6 B$ virgin females. Similar genotypes were used to test one or two copies of $\mathrm{P}\left[w^{+}, d a b^{+}\right]$for rescue, except that the males were homozygous for one or two independent second chromosome insertions of $\mathrm{P}\left[\mathrm{w}^{+}, d a b^{+}\right]$. To introduce three or four copies of $\mathrm{P}\left[w^{+}, d a b^{+}\right]$, males and females were both homozygous for one or two second chromosome insertions of $\mathrm{P}\left[\mathrm{w}^{+}, d a b^{+}\right]$. Similar results were observed when different combinations of the independent $\mathrm{P}\left[\mathrm{w}^{+}, d a b^{+}\right]$insertions were used (data not shown). To generate $\mathrm{P}\left[a d h^{+}, a b 1^{l_{\text {ys-}}}\right] ; a b 1^{-} d a b^{-} / a b 1^{-} d a b^{+}$progeny, a cross was set up between white; $a b 1^{1} / T M 6 B$ males and $\mathrm{P}\left[a d h^{+}, a b l^{l y s-}\right] ; D f(3 L)$ std11/TM6B females. To introduce $\mathrm{P}\left[\mathrm{w}^{+}, d a b^{+}\right]$into this background, males homozygous for two independent second chromosome insertions of $\mathrm{P}\left[\mathrm{w}^{+}, \mathrm{dab} \mathrm{b}^{+}\right]$ were used in the cross. $\mathrm{P}\left[a d h^{+}, a b 1^{l y s-}\right]$ is described in Henkemeyer et al. (1990).

Embryo collections for immunohistochemistry To eliminate balancer chromosomes from populations of stained animals, adults bearing the appropriate mutant chromosomes were crossed to either Canton-S, Oregon-R, or Tokyo wild stocks. The outcrossed progeny were then used to generate collections of staged embryos. For example, to generate protein-null $\mathrm{dab}^{-}$ embryos for immunohistochemistry, male $D f(3 L)$ st100.62/ Canton-S flies were crossed to female $D f(3 L)$ stE34/Tokyo wild virgin females. To generate $a b 1^{-} d a b^{-}$pros $^{-}$triple mutant embryos, the pros ${ }^{M 4}$ allele was recombined onto the $D f(3 L) s t / 7$, $d a b^{m 2}$, and $D f(3 L) s t d 11$ chromosomes. Df $(3 L)$ std11, pros ${ }^{M 4}$ / Canton-S virgins were mated to $D f(3 L) s t / 7$, dab ${ }^{m 2} \mathrm{pros}^{\mathrm{M4}} / \mathrm{Can}$ ton-S males. Recombination in these females would affect only a few of the embryos observed because the recombination distance between pros and $a b l$ is $\sim 6 \mathrm{cM}$. For $a b l^{-}$pros $^{-}$double mutant analysis, the pros ${ }^{M 4}$ allele was recombined onto the $a b l^{1}$ chromosome. $D f(3 L) s t / 7$, pros ${ }^{17} /$ Canton-S virgins were mated to $a b I^{1}(254 \mathrm{C})$, pros $^{\mathrm{M} 4} /$ Canton S males. Mutant phenotypes from such crosses were confirmed in crosses using a TM3 balancer chromosome that carries a $\mathrm{P}[$ lacZ] transposon (gift of Dr. Y. Hiromi, Princeton University, NJ) to identify nonmutants in the populations of stained embryos. Embryos were stained with anti- $\beta$-galactosidase antibodies (Promega) to distinguish embryos bearing the balancer chromosome from those mutant for $a b l, d a b$, or pros.

Embryo collection for Western blot analysis A cross was set up to generate zygotes that had three, two, one, or zero copies of the $d a b$ gene: $D p(3 ; 3) s t^{+} g 18 / D f(3 L) s t g 18$ males were crossed to $D f(3 L)$ stE5/TM $6 B$ virgin females. $D p(3 ; 3) s t^{+} g 18$ is a tandem duplication that carries two copies of $72 \mathrm{E} 2-74 \mathrm{~F} 4 ; D f(3 L)$ stg 18 is a deletion of this same interval. $D f(3 L)$ stE5 deletes $72 E 2$ to 73D4. A 4-hr egg lay from this cross was aged $12 \mathrm{hr}$ at $25^{\circ} \mathrm{C}$. Individual embryos were picked and dechorionated by hand on double-stick tape. The embryos were mounted in $1 \times$ PBS with $10 \%$ glycerol and scored by bright-field microscopy for head defects that are found in $D f(3 L) s t E 5 / D f(3 L)$ stg 18 embryos (F.B. Gertler and F.M. Hoffmann, unpubl.). Ten mutant and 10 wildtype embryos were each pooled in $10 \mu l$ of $1 \times \mathrm{PBS}$ and stored on ice. Thirty microliters of boiling $2 \times$ sample buffer was added, and the samples were homogenized with a tissue grinder while in a $100^{\circ} \mathrm{C}$ temperature block. The samples were boiled for 10 min and spun for $10 \mathrm{~min}$ in a microcentrifuge before use.

\section{Immunohistochemistry}

Whole embryos were fixed, dechorionated, and devitellinized using the method of Thomas et al. (1988). Following rehydration in PBS [10 mM sodium phosphate $(\mathrm{pH} 7.4), 150 \mathrm{~mm}$ sodium chloride], embryos were blocked for a minimum of $3 \mathrm{hr}$ with 6 changes of PBS containing $0.2 \%$ BSA and $0.1 \%$ Triton X-100 (PBT); 5\% normal goat serum (NGS) (Sigma) was added to the PBT for the final $30 \mathrm{~min}$ of blocking. Embryos were incubated overnight at $4{ }^{\circ} \mathrm{C}$ in antibody diluted in PBT $+5 \%$ NGS. Antibodies were used at the following dilutions: mAb BP102 antibody (gift of C. Goodman, University of California, Berkeley), $1: 300$; mAb 4D9 /anti-engrailed, gift of N. Patel, University of California, Berkeleyl, $1: 25$; a second anti-engrailed monoclonal antibody (gift of S. Carroll, University of Wisconsin, Madison), $1: 500$; anti-dab, $1: 100$ (final concentration of $1 \mu \mathrm{g} / \mathrm{ml}$ ); anti-ßgalactosidase (Promega), 1:300. After incubation with the primary antibody, the embryos were washed for $3 \mathrm{hr}$ with six changes of PBT. During the last wash, $5 \%$ NGS was added. The embryos were then incubated for $2 \mathrm{hr}$ at $4^{\circ} \mathrm{C}$ with a bioti- 
nylated goat anti-rabbit or goat anti-mouse secondary antibody (Vector Labs or Boehringer Mannheim) diluted 1:600 in PBT $+5 \%$ NGS. The embryos were washed again and incubated for $2 \mathrm{hr}$ at $4^{\circ} \mathrm{C}$ with Streptavidin conjugated to horseradish peroxidase (HRP) (Vector Labs or Boehringer Mannheim) diluted $1: 300$. The secondary and tertiary reagents were preabsorbed against wild-type, fixed embryos before use. The embryos were washed as described above and placed in TBS [10 mM Tris $/ \mathrm{pH}$ 7.5), $150 \mathrm{~mm}$ sodium chloride] containing $20 \mathrm{mg} / \mathrm{ml}$ of diaminobenzidine (Sigma) and $0.0003 \%$ hydrogen peroxide. The reaction was carried out until staining was clearly visible under a dissecting microscope (5-15 $\mathrm{min})$. The embryos were rinsed three times with PBS, once in $40 \%$ ethanol, once in $70 \%$ ethanol, and twice with absolute ethanol and cleared in methyl salicylate (Sigma), or, for nerve cord dissection, $90 \%$ glycerol. Embryos were observed and photographed on a Zeiss Axiophot equipped with Nomarski optics using $20 \times$ or $40 \times$ objectives, or under oil immersion with $63 \times$ or $100 \times$ objectives.

\section{Production of antibodies}

Bacterial dab and abl proteins for immunization were generated using the pGEX vectors (Smith and Johnson 1988). A 1.4-kb EcoRI-HindIII fragment (coding for amino acids 1600-2022 of dab) was subcloned into pGEX1, and a $0.7-\mathrm{kb} B a m H I$ fragment (coding for amino acids 81-323 of abl) was subcloned into pGEX2. Fusion proteins were gel purified by preparative SDSpolyacrylamide gel electrophoresis followed by electroelution. All immunizations were in MPL + TDM adjuvant (RIBI Immunochem). Female New Zealand white rabbits were immunized at two or three sites by subcutaneous injection with $200-400 \mu \mathrm{g}$ of gel-purified fusion proteins. Animals were boosted every month after the primary injection; sera were collected 7-10 days after each boost. The anti-dab antibodies and anti-abl2.1 antibodies were affinity purified (Gertler 1992).

\section{Library screening}

Unless otherwise noted, routine molecular biology was conducted essentially as described in Sambrook et al. (1989). The chromosome walk was initiated with a DNA fragment from 14.8.5 (McKeown et al. 1987) in a cosmid library (gift of J. Tamkun, University of California, Santa Cruz). The cosmid library was constructed using a P-element transformation vector containing the white ${ }^{+}$gene as a scorable marker. Cosmid DNA at a concentration of $800 \mu \mathrm{g} / \mathrm{ml}$ was microinjected into white embryos containing a copy of the $\Delta 2-3$ transposase-producing element (Robertson et al. 1988).

A 12- to 24-hr plasmid cDNA library (Brown and Kafatos 1988) was screened with $\sim 55 \mathrm{~kb}$ of DNA isolated from cosmids (corresponding to $55-110 \mathrm{~kb}$ in Fig. 3). An adult head cDNA library in $\lambda$-ZAP (Stratagene) (gift of J. Warmke, University of Wisconsin, Madison) was screened with $d a b$ cDNA probes to obtain clones extending more $5^{\prime}$.

\section{DNA sequencing and analysis}

$d a b$ DNA encompassing 8805 nucleotides, including 999 derived from clones of genomic DNA immediately $5^{\prime}$ to the beginning of the longest cDNA clone, was sequenced using the Sequenase 2.0 system (U.S. Biochemical) or the fmole kit (Promega) (Gertler 1992). (The sequence has been deposited in GenBank.) The sequence of the longest cDNA RACE product is identical to bases 751-1098, with the addition of a guanine nucleotide at its $5^{\prime}$ end (indicated as the putative cap site in the sequence). The remainder of the sequence (1000-8805) was de- rived from cDNA clones. RACE was conducted as described by Frohman et al. (1988) and Gertler (1992). Southern analysis using $d a b$ cDNA probes indicated that the longest RACE product was similar in size to the longest cloned RACE product recovered (Gertler 1992).

\section{Immunoprecipitation}

Drosophila S2 cells were maintained under standard conditions (Schneider 1972). S2 cells underwent lysis at a density of $5 \times 10^{6}$ cells $/ \mathrm{ml}$ in ice-cold IP buffer: $50 \mathrm{~mm}$ Tris $(\mathrm{pH} 7.5), 150$ $\mathrm{mm} \mathrm{NaCl}, 5 \mathrm{~mm}$ EDTA, $5 \mathrm{~mm}$ EGTA, $1 \%$ Triton X-100. The following were added to the IP buffer immediately before lysis: $10 \mu \mathrm{g} / \mathrm{ml}$ each of leupeptin, pepstatin, and aprotinin; $2 \mathrm{~mm}$ PMSF; $0.5 \mathrm{U} / \mathrm{ml}$ of $\alpha$-macroglobulin; $1 \mathrm{mM}$ sodium orthovanadate (all from Boehringer Mannheim Biochemicals). The lysates were suspended by pipetting, incubated on ice for $30 \mathrm{~min}$, and clarified by centrifugation at $10,000 \mathrm{rpm}$ in an SS34 rotor at $4^{\circ} \mathrm{C}$ for $10 \mathrm{~min}$. All lysates were precleared with $5 \mu \mathrm{l} / \mathrm{ml}$ of a $50 \%$ slurry of protein A-agarose (Pierce Co.). Antibodies were added at the following concentrations: anti-abl2.1 or anti-dab antibody at $1 \mu \mathrm{g} / \mathrm{ml}$, preimmune immunoglobulin purified by protein A chromatography (Pierce Co.) at $10 \mu \mathrm{g} / \mathrm{ml}$, and anti-phosphotyrosine at $3.3 \mu \mathrm{g} / \mathrm{ml}$. Preimmune immunoglobulins were purified from the serum of rabbits 2385 and 2382 that were later immunized with abl and dab, respectively. The anti-phosphotyrosine antibody was a $1: 1$ mixture of mAb4G10 (UBI), and the anti-phosphotyrosine monoclonal antibody from Oncogene Science. Before its addition, the anti-phosphotyrosine antibody at $100 \mu \mathrm{g} / \mathrm{ml}$ was incubated with either $100 \mu \mathrm{M}$ phospho-Lserine or phospho-L-tyrosine (Sigma) for $1 \mathrm{hr}$ at $4^{\circ} \mathrm{C}$ in IP buffer. The IPs were incubated overnight at $4^{\circ} \mathrm{C}$ with gentle rocking. Then $5 \mu \mathrm{l} / \mathrm{ml}$ of a $50 \%$ slurry of protein A-agarose was added to remove the rabbit antibodies, and $30 \mu \mathrm{l} / \mathrm{ml}$ of the slurry was added to remove the monoclonal antibodies. After rocking for 2-4 hr, the protein A-agarose was retrieved by centrifugation at $1500 \mathrm{rpm}$ at $4^{\circ} \mathrm{C}$ for $2 \mathrm{~min}$. Agarose pellets were washed three times in ice-cold IP buffer and boiled in $2 \times$ sample buffer (Laemmli 1970). For inhibition in vivo of tyrosine phosphatases, 100 $\mu \mathrm{M}$ sodium orthovanadate (Sigma) plus $2 \mathrm{mM} \mathrm{H}_{2} \mathrm{O}_{2}$ was added to the culture media $30 \mathrm{~min}$ before harvesting the $\mathrm{S} 2$ cells.

\section{Western analysis}

Samples were subjected to polyacrylamide gel electrophoreses (PAGE) on a 5\% gel (Laemmli 1970). After electrophoresis, the proteins were transferred to nitrocellulose by electroblotting in transfer buffer (14.46 grams/liter of glycine, 3 grams/liter of Tris base, $5 \%$ methanol). The buffer was chilled before use, and the transfer was performed in a Bio-Rad Minitransfer box at 35 $\mathrm{V}$ overnight at $4^{\circ} \mathrm{C}$ with a current limit of $0.8 \mathrm{amps}$. Blots were blocked for $1 \mathrm{hr}$ in blocking buffer: PBS $+0.05 \%$ Tween $20+5 \%$ BSA. Blots were then incubated overnight at $4^{\circ} \mathrm{C}$ in fresh blocking buffer with primary antibodies added at the following concentrations: anti-abl and anti-dab at $0.15 \mu \mathrm{g} / \mathrm{ml}$, preimmune immunoglobulins at $1.5 \mu \mathrm{g} / \mathrm{ml}$, and $\mathrm{mAb} 4 \mathrm{G} 10$ (in the absence of Tween) at $1 \mu \mathrm{g} / \mathrm{ml}$. Blots were washed for $1 \mathrm{hr}$ in PBS $+0.1 \%$ Tween 20 (PBST) with at least 10 changes of buffer. Unlabeled goat anti-rabbit or goat anti-mouse antibodies (Boehringer Mannheim Biochemicals) were added at $1 / 2000$ in blocking buffer, and the blots were incubated for $1 \mathrm{hr}$. After washing, HRP-conjugated swine anti-goat (Boehringer Mannheim Biochemicals) antibody was added at $1 / 2000$ in blocking buffer, and the blots incubated for $1 \mathrm{hr}$. The blots were washed in PBST, incubated in ECL detection reagent (Amersham), and exposed to XAR5 film (Kodak). 


\section{Acknowledgments}

We are grateful to Drs. Cayetano Gonzalez, Janos Gausz, Ethan Bier and Chris Doe for the many stocks used for pros complementation tests. We thank Drs. Mark Seeger and Nipam Patel for suggestions on nerve cord preparation for photography and Drs. Seth Blair, Sean Carroll, Corey Goodman, Nipam Patel, and Tony Pawson for the gift of antibodies. We thank Drs. John Tamkun, Jeff Warmke, and Nick Brown for gifts of cosmid and cDNA libraries. Randy Bennett and Kay Rashka provided technical advice and assistance on antibody production and S2 cell culture respectively. We thank Terry Stewart for help with photography. Dr. Eric Liebl provided comments on the manuscript. Funding for this work was obtained from the National Institutes of Health, including CA49582 to F.M.H., Cancer Center Core support CA07175 to H.C. Pitot, and predoctoral training grants GM07133 for K.K.H. and CA09135 for F.B.G. F.M.H. is the recipient of a Faculty Research Award from the American Cancer Society.

The publication costs of this article were defrayed in part by payment of page charges. This article must therefore be hereby marked "advertisement" in accordance with 18 USC section 1734 solely to indicate this fact.

\section{References}

Artavanis-Tsakonas, S. 1988. The molecular biology of the Notch locus and the fine tuning of differentiation in Drosophila. Trends Genet. 4: 95-100.

Belote, J.M., F.M. Hoffmann, M. Mckeown, R.L. Chorsky, and B.S. Baker, B.S. 1990. Cytogenetic analysis of chromosome region 73AD of Drosophila melanogaster. Genetics 125: 783-793.

Bennett R.L. and F.M. Hoffmann. 1992. Increased levels of the Drosophila abl tyrosine kinase in nerves and muscles: Subcellular localization and mutant phenotypes imply a role in cell-cell interactions. Development 116: 953-966.

Boggs, R., P. Gregor, S. Idriss, J. Belote, and M. McKeown. 1987. Regulation of sexual differentiation in $D$. melanogaster via alternative splicing of RNA from the transformer gene. Cell 50: 739-747.

Brown, N. and F. Kafatos. 1988. Functional Drosophila cDNA libraries from Drosophila embryos. I. Mol. Biol. 203: 425437.

Cavener, D.R. 1987. Comparison of the consensus sequence flanking translational start sites in Drosophila and vertebrates. Nucleic Acids Res. 4: 1353-1361.

Chou, T.B., Z. Zachar, and P. Bingham. 1987. Developmental expression of a regulatory gene is programmed at the level of splicing. EMBO I. 6: 4095-4104.

Devereaux, J., P. Haeberli, and O. Smithies. 1984. A comprehensive set of sequence analysis programs for the VAX. $\mathrm{Nu}$ cleic Acids Res. 12: 387-395.

Doe, C.Q., Q. Chu-LaGraff, D.M. Wright, and M.P. Scott. 1991. The prospero gene specifies cell fates in the Drosophila central nervous system. Cell 65: 451-464.

Elkins, T., K. Zinn, L. McAllister, F.M. Hoffmann, and C.S. Goodman. 1990. Genetic analysis of a Drosophila neural cell adhesion molecule: Interaction of fasciclin $I$ and Abelson tyrosine kinase mutations. Cell 60: 565-575.

Frohman, M.A., M.K. Dush, and G.R. Martin. 1988. Rapid production of full length cDNA from rare transcripts: Amplification using a single gene-specific oligonucleotide primer. Proc. Natl. Acad. Sci. 85: 8998-9002.

Gertler, F.B. 1992. "Genetic modifiers of the Drosophila $a b 1$ mutant phenotype." Ph.D. thesis, University of Wisconsin,
Madison.

Gertler, F.B., R.L. Bennett, M.J. Clark, and F.M. Hoffmann. 1989. Drosophila $a b l$ tyrosine kinase in embryonic CNS axons: A role in axonogenesis is revealed through dosage-sensitive interactions with disabled. Cell 58: 103-113.

Gertler, F.B., J.S. Doctor, and F.M. Hoffmann. 1990. Genetic suppression of mutations in the Drosophila $a b l$ proto-oncogene homolog. Science 248: 857--860.

Heffetz, D., I. Bushkin, R. Dror, and Y. Zick. 1990 The insulinomimetic agents $\mathrm{H}_{2} \mathrm{O}_{2}$ and vanadate stimulate protein tyrosine phosphorylation in intact cells. J. Biol. Chem. 265: 2896-2902.

Henkemeyer, M.J., F.B. Gertler, W. Goodman, and F.M. Hoffmann. 1987. The Drosophila Abelson proto-oncogene homolog: Edentification of mutant alleles that have pleiotropic effects late in development. Cell 51: 821-828.

Henkemeyer, M., S.R. West, F.B. Gertler, and F.M. Hoffmann. 1990. A novel tyrosine kinase-independent function of Drosophila $a b l$ correlates with proper subcellular localization. Cell 63: 949-960.

Hoffmann, F.M. 1991. Drosophila $a b l$ and genetic redundancy in signal transduction. Trends Genet. 7: 351-355.

Hunter, T. and J.A. Cooper. 1986. Viral oncogenes and tyrosine phosphorylation. In The enzymes (ed. P.D. Boyer and E.G. Krebs|, pp. 191-246. Academic Press, Orlando, Florida.

Jan, L.Y. and Y.N. Jan. 1982. Antibodies to horseradish peroxidase as specific neuronal markers in Drosophila and in grasshopper embryos. Proc. Natl. Acad. Sci. 79: 2700-2704.

Konopka, J.B., S.M. Watanabe, and O.N. Witte. 1984. An alteration of the human c-abl protein in $\mathrm{K} 562$ leukemia cells unmasks associated tyrosine kinase activity. Cell 37: 10351042.

Laemmli, U.K. 1970. Cleavage of structural proteins during the assembly of the head of bacteriophage T4. Nature 227: 680 685.

Lindsley, D.L. and G.G. Zimm. 1992. The genome of Drosophila melanogaster. Academic Press, New York.

Matsuzaki, F., K. Koizumi, C. Hama, T. Yoshioka, and Y. Nabeshima. 1992. Cloning of the Drosophila prospero gene and its expression in ganglion mother cells. Biochem. Biophys. Res. Commun. 182: 1326-1332.

McKeown, M., J.M. Belote, and B.S. Baker. 1988. A molecular analysis of transformer, a gene in Drosophila melanogaster that controls female differentiation. Cell 48: 489-499.

Query, C., R. Bently, and J. Keene. 1989. A common RNA recognition motif identified within a defined U1 RNA binding domain of the 70k Ul snRNP protein. Cell 57: 89-101.

Robertson, H.M., C.R. Preston, R.W. Philips, D. Johnson-Schitz, W.K. Benz, and W.R. Engels. 1988. A stable source of P element transposase in Drosophila melanogaster. Genetics 118: $461-470$.

Sambrook, J., E.F. Fritsch, and T. Maniatis. 1989. Molecular cloning: A laboratory manual. Cold Spring Harbor Laboratory Press, Cold Spring Harbor, New York.

Schneider, I. 1972. Cell lines derived from late embryonic stages of Drosophila melanogaster. I. Embryol. Exp. Morphol. 27: 353-365.

Simpson, P. 1983. Maternal-zygotic gene interactions during formation of the dorsoventral pattern in Drosophila embryos. Genetics 105: 615-632.

Smith, D.B. and K.S. Johnson. 1988. Single-step purification of polypeptides expressed in Escherichia coli as fusions with glutathione-S transferase. Gene 67: 31-40.

Surowy, C., V. Van Santen, S. Scheib-Wixed, and R. Spritz. 1989. Direct, sequence-specific binding of the human Ul small nuclear RNA. Mol. Cell. Biol. 9: 4179-4186. 
Theissen, H., M. Etzerodt, R. Reuter, C. Schneider, F. Lottspeich, P. Argos, R. Luhrmann, and L. Philipson. 1986. Cloning of the human cDNA for the U1 RNA associated 70k protein. EMBO I. 5: 3209-3217.

Thomas, J.B., S.T. Crews, and C.S. Goodman. 1988. Molecular genetics of the singleminded locus: A gene involved in the development of the Drosophila nervous system. Cell 52: 133-141.

Vaessin, H., E. Grell, E. Wolff, E. Bier, L.Y. Jan, and Y.H. Jan. 1991. prospero is expressed in neuronal precursors and encodes a nuclear protein that is involved in the control of axonal outgrowth in Drosophila. Cell 67: 941-953. 


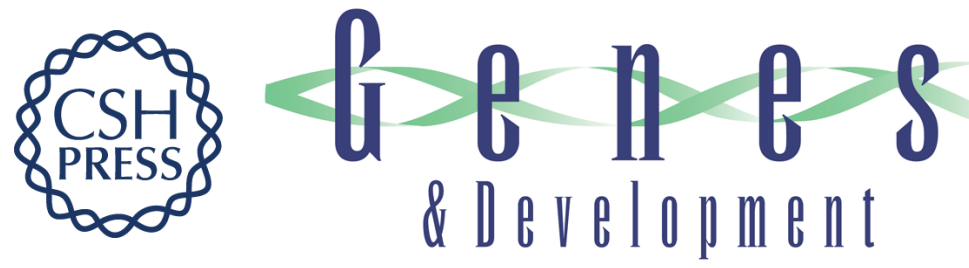

\section{Dosage-sensitive modifiers of Drosophila abl tyrosine kinase function: prospero, a regulator of axonal outgrowth, and disabled, a novel tyrosine kinase substrate.}

F B Gertler, K K Hill, M J Clark, et al.

Genes Dev. 1993, 7:

Access the most recent version at doi:10.1101/gad.7.3.441

References This article cites 31 articles, 9 of which can be accessed free at: http://genesdev.cshlp.org/content/7/3/441.full.html\#ref-list-1

License

Email Alerting Service

Receive free email alerts when new articles cite this article - sign up in the box at the top right corner of the article or click here.

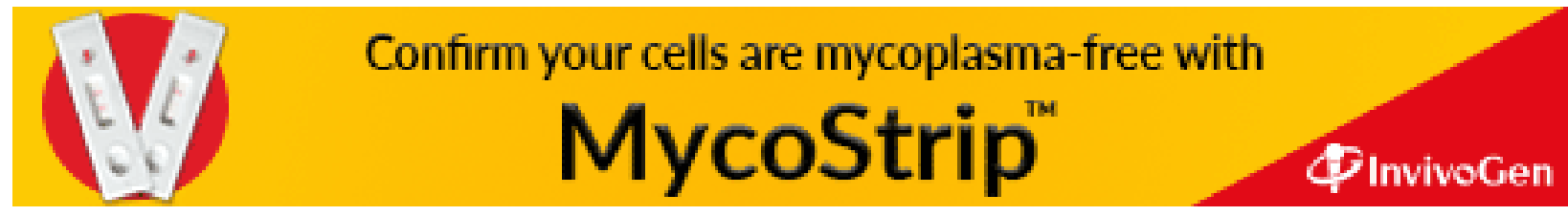

